\title{
Ethical theory, ethnography, and differences between doctors and nurses in approaches to patient care
}

\author{
David W Robertson University of Toronto Medical School, Toronto, Canada
}

\begin{abstract}
Objectives-To study empirically whether ethical theory (from the mainstream principles-based, virtue-based, and feminist schools) usefully describes the approaches doctors and nurses take in everyday patient care.

Design-Ethnographic methods: participant observation and interviews, the transcripts of which were analysed to identify themes in ethical approaches.

Setting-A British old-age psychiatry ward.

Participants-The more than 20 doctors and nurses on the ward.

Results-Doctors and nurses on the ward differed in their conceptions of the principles of beneficence and respect for patient autonomy. Nurses shared with doctors a commitment to liberal and utilitarian conceptions of these principles, but also placed much greater weight on relationships and character virtues when expressing the same principles. Nurses also emphasised patient autonomy, while doctors were more likely to adovate beneficence, when the two principles conflicted. Conclusion-The study indicates that ethical theory can, contrary to the charges of certain critics, be relevant to everyday health care - if it (a) attends to social context and (b) is flexible enough to draw on various schools of theory.
\end{abstract}

\section{Introduction and purpose}

Can mainstream, principles-based ethical theory usefully describe the approaches doctors and nurses take to patient care? Many doctors and nurses, and even some writers on health care morality, ${ }^{1-3}$ charge that mainstream ethical theory is too removed from lived reality to shed light on the way health care professionals do their work. This study explores the question empirically in a psychiatric ward, using ethnography. Ethnography is a sociological methodology for exploring everyday life, in which the researcher characteristically becomes a participant

\section{Key words}

Medical ethics; ethnography; combining empirical research and ethical theory. observer, studying the sub-culture under examination as a member of it. ${ }^{4} \mathrm{I}$ observed the ward in the roles first of junior nurse, and later of medical student.

I begin by describing two elements of the study's foundation: the aspects of health care observed, and the nature of the ethical theory explored. First, in examining empirically the ethical perspectives of staff, what aspects of health care are relevant to observe? Bioethics most typically focuses on such momentous questions as abortion, euthanasia and withholding life-sustaining treatment. Certain writers in moral philosophy ${ }^{5}$ and medical sociology, ${ }^{67}$ however, argue the ethical significance of all aspects of health care including less dramatic decisions, such as what do patients eat for breakfast and how much opportunity? do they have to talk with their doctors. Such issues affect the quality of care for all patients, not only those whose cases imply life-and-death considerations. The present study focuses on such everyday aspects of care; aspects largely neglected in the ethics literature.

Second, the theoretical approaches explored included mainstream, principles-based health care ethics, characteristically presented by Beauchamp and Childress ${ }^{8}$ (who give a mostly liberal-utilitarian interpretation of the principles) and Gillon ${ }^{9}$ (whose approach is more pluralist), and founded on three or four principles (respect for patient autonomy, justice, beneficence and - often - non-maleficence). This dominant theory has incurred criticism from proponents of casuistic, virtue-based, and feminist ethical theory, for its abstraction, focus on universality, and paucity of terms for describing moral character and the morality of relationships. Beauchamp and Childress ${ }^{8}$ have responded to the critics by advocating a theoretical amalgam based on their four principles but including aspects of their critics' theories, to reflect the range of moral frameworks at play in Western societies and even within individuals. The present study therefore also explores the relevance of neo-Aristotelian virtue theory with its account of personal character, ${ }^{10}$ and feminist theory, which focuses on relationships. ${ }^{11}$

In sum, the study used ethnography to explore whether an amalgam of ethical theories sheds useful light on patient care. This article describes first the 
literature on the ethical approaches of practitioners, then this study's methods, results, and recommendations for practice, education and further research.

\section{Literature on the ethical approaches of practitioners}

Research into the ethical approaches of health care professionals generally falls into two categories: attitudinal surveys, and ethnographic studies of practice. The present study aims to incorporate strengths of both. The attitudinal surveys, whether through questionnaires with simulated cases, ${ }^{12-14}$ or observing role-playing exercises, ${ }^{15}$ allow researchers to construct simulated situations structured according to theoretical ethics (as is also true of studies of decision-making ethics from clinical notes).${ }^{16}$ All of these methods, though, stand at one remove from practice.

In contrast, ethnographic studies of practice ${ }^{17-19}$ that address, or come close to addressing, health care ethics, while rare, ${ }^{201}$ have the advantage of immediacy to practice but the disadvantage that they generally (with the exception of Frohock and Fox and Swazey) lack even a passing explicit reference to a philosophical ethical framework. Jennings ${ }^{21}$ proposes uniting the ethical articulation that attitude surveys can accommodate and the immediacy of ethnography, since "most writings in bioethics still draw faintheartedly and unimaginatively, or not at all, on social scientific studies that address the setting, institutional context, and cultural forces relating to the bioethical problem at hand". The present study takes up Jennings's challenge, employing the following method.

\section{Method}

The study's methodology combines an analytical framework from ethics and ethnography's techniques for studying everyday practice. I will explain first the setting, second the ethnographic method of observation, and third the ethical analytical framework.

\section{Setting}

The study examined old-age psychiatry, which is rife with ethical tensions between professional beneficence and respect for patient autonomy. The mandate of the ward studied was to stabilise and assess patients from a socio-economically diverse population, prior to referral back to their homes or to an institution providing longer term care. Patients were men and women over 65 years of age, diagnosed with either a depressive disorder or dementia. The staff-to-patient ratio was high: typically four nurses and between two and four doctors for a maximum of twelve patients. The ranks of both the medical and the nursing teams included men and women, and a range of ages.

\section{Observation}

During the ten weeks of ethnographic empirical observation, I worked 21 shifts on the ward, with doctors (whom I accompanied, as a medical student, in their daily work, including interactions with patients and professional meetings) and nurses (with whom I worked under an honorary contract as a nursing assistant). Fieldnotes of ethically relevant events were taken during informal interviews, meetings of staff and observations of patient care. Events were defined as specific actions or verbal communications made by staff and indicating ethically laden decision-making and attitudes, for example, a verbal exchange between two doctors debating the administration of medication against a patient's will, or a nurse's explanation that a patient should be encouraged to brush her own teeth to maximise self-sufficiency. In all, approximately 400 events were recorded, about 20 per shift.

\section{Analysis}

One of the tenets of ethnography is that the researcher may begin the study with certain research questions, but ought not to impose a pre-set analytical framework on the data: the framework should arise from the data, as the researcher begins to discern patterns in it. This study began with the question: can various schools of health care theory usefully describe decision-making and attitudes on ac psychiatric ward? Although I had surveyed the literature on these ethical schools before beginning fieldwork, I waited until the fieldwork was under way before assembling the analytical framework in the following manner. Throughout the fieldwork, I tested the relevance of the three bodies of theory by assessing which theory (or combination of theories) best described a sample of events. In this way, an original framework aptly applicable to all the events evolved in tandem with the fieldwork. The following examples of events observed on the ward illustrate how feminist and virtue theory helped refine the mainstream principle of beneficence, as reflected in the final framework (see figure 1).

1. A doctor considering the treatment of a psychiatric out-patient who likely has cancer:

"I think she should be endoscoped. I've been caught before thinking that it's a carcinoma when it's not." A firm diagnosis would be helpful since if "she won't be here next Christmas", ie, it is inoperable, palliative care should be envisioned: the "GP could give a bit of MST (morphine sulphate tablets) ... if she's in pain; a little MST might do the trick. But if she's going to live another ten years, you don't want her addicted to morphine".

\section{A nurse explaining his philosophy of care:}

"By the end of the day, a person has to make a moral choice about (how much to care). Something to do with general outlook and receptivity, which I 


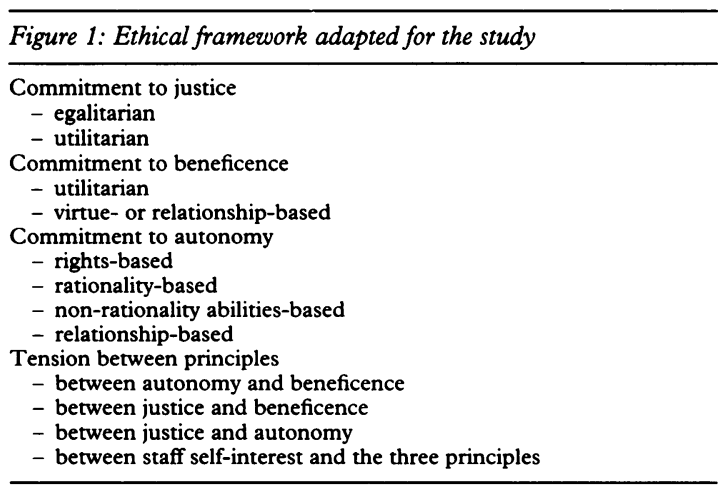

don't think can be encapsulated in a training school." The nurse went on to talk about the importance of "engaging" with the patient.

Both 1 and 2 express beneficence. In 1 , the doctor is concerned with balancing the benefits of pain palliation and the risks of addiction: a typical utilitarian deliberation. However, 2 includes another important facet of beneficence: that of professional virtue and the relationship between doctor and patient, seen in the emphasis on moral attitude or outlook, and engaging in relationships with patients. I therefore labelled 1 "utilitarian beneficence" (from the mainstream framework) and 2 "virtue- or relationship-based beneficence" (reflecting virtue and feminist theory). Both labels figure as subcategories in the adaptation of the four-principles framework. I determined the rest of the study's ethical framework similarly; the result was the three principles schema in figure 1 .

A methodological comment is necessary here for readers familiar with ethnography. Ethnographic data about a given social group typically give rise to an analytical framework that helps explain the group and its attributes. In contrast, the present study fitted elements of pre-existing ethical theory to ethnographic data. Some ethnographers might therefore criticise the study on methodological grounds, for not allowing the data to lead to their own framework without reference to previous theory. However, the different approach taken here has the advantages of (a) putting existing ethical theory to a systematic and practical test, and (b) systematically describing the ethical approaches of doctors and nurses. Also, the categories of the ethical framework used to analyse the data were determined only after the data were collected. The categories use ethical theory, but only aspects of theory found applicable to observations on the ward. Theory was therefore not imposed on the data; the data and the theory both informed the analytical framework.

Once the fieldwork ended and the analytical framework had been finalised, the fieldnotes were transcribed, coded and analysed according to the categories of the framework, using a content analysis software package, HyperRESEARCH. The software counted the number of events falling under each category, generating frequency statistics and indicating the salience of each category for doctors and nurses, respectively. No further statistical analysis was performed. The frequency statistics ensure that the study's data were methodically collected and its conclusions justified. The validity of any more sophisticated statistical analysis would be tenuous, given relatively low $\mathrm{N}$ values, and the fact that ethnographic data do not allow the same controls that, for example, survey methods permit. It also allowed easy reference to the text of the events. The study's conclusions are therefore based on both quantitative and qualitative data. The coding process was verified by two colleagues, along lines recommended by Miles and Huberman ${ }^{22}$ and Burnard. ${ }^{23}$ Each colleague coded two observation transcripts. I compared my colleagues' coding with mine and discussed with them any points where we differed. Our coding accorded closely, except for two points which led me to adjust the analytical framework to its present form. I also presented the results and conclusions to individuals on the ward and to the group as a whole. Their response confirmed the validity of the findings, in that they rang true with the experience of staff.

Before proceeding with the results, I will briefly describe a final aspect of the method. Ethnography emphasises the relevance of social context to socia patterns observed by the researcher. ${ }^{1}$ One can infer that an ethnographic study of ethics on a hospital ward should provide an account of whether the social context of the ward was relevant to ethical patterns observed. Therefore, simultaneously to the ethical case study, and using the same fieldnotes, I conducted a sociological case study, for which I constructed a second analytical framework, drawing on the work of Guillemin and Holmstrom ${ }^{17}$ and assessing, most importantly, the professional goals of staff. This article, for reasons of space, will discuss only the highlights of the sociological case study, to demonstrate that social context does indeed help account for ethical patterns. The following two sections outline the principal results.

\section{Results}

This section will first present the highlights of the sociological case study, and then, in more detail, those of the ethical case study. The most salient sociological results, described here for brevity's sake without corroborating qualitative and quantitative evidence, pertained to differences between doctors and nurses in their professional goals and attitudes towards technology. Doctors tended to put far more emphasis than nurses on three goals: (i) clinical problem-solving (defined by the steps of assessing a situation, pinpointing a problem, then determining and pursuing a remedy); (ii) assessing and 
maximising organic function, and (iii) research. Nurses appeared to place a higher priority on daily care and fostering patient normality and independence. The sociological case study also revealed that the "technological imperative", or tendency to use technology (specifically drugs, electroconvulsive therapy, and diagnostic tests) and technological explanations rather than social or psychological alternatives, was especially evident amongst doctors on the ward. These results help explain the ethical findings, presented next.

This discussion of the ethical case study draws conclusions about doctors' and nurses' commitments to justice, beneficence and patient autonomy, and about tensions between these principles. JUSTICE denotes fairness, desert, entitlement, and equitableness. Its prime relevance in health care is in the allocation of scarce resources to needy patients, and the most common perspectives on justice are utilitarian, libertarian, communitarian, and egalitarian. In the study, although the utilitarian and communitarian perspectives may be discerned behind National Health System policies, day-to-day resource allocation within the ward was observed to be discussed exclusively along egalitarian lines, concerned with the equal worth and entitlement of patients. (It is possible that tacit rationing along utilitarian lines occurred, but I observed no evidence of this.)

Doctors and nurses exercised this egalitarian approach in an environment where resources were clearly insufficient to respond to all patient needs and a "beds crisis" was a constant condition of practice, a phenomenon illustrated by the following exchange between a doctor and a group of social workers from the ward's catchment area.

Doctor: The bed situation is very tight ... sixteen patients waiting for purely financial [bed shortage] reasons. The directorate will really have to call a crisis meeting to decide what to do about this. Perhaps we could shuffle some beds.

Social worker: We have been trying to negotiate with the geriatrician.

Second SW: This is very bad for patients.

Doctor: The situation is just about getting to gridlock [so] we should put people's names down for treatment if they need it, but ... [doctor implies the unlikelihood that all the people whose names were put down would actually receive care].

Commitment to BENEFICENCE was central for all staff. Figure 2 indicates that doctors and nurses were each observed to value beneficence highly in a large number of events observed on the ward (47 for doctors; 56 for nurses). The comments and actions of both doctors and nurses suggested they were motivated to similarly high degrees by a utility-based conception of beneficence (44 events for doctors; 40 for nurses). Events illustrating this conception conveyed

\begin{tabular}{|l|c|c|}
\hline \multicolumn{3}{|c|}{ Figure 2: Conceptions of beneficence by occupational group } \\
\hline & \multicolumn{3}{|c|}{ Number of events } \\
\hline & Doctors & Nurses \\
\hline Utility-based & 44 & 40 \\
\hline Virtue-/relationship-based & 3 & 16 \\
\hline Total & 47 & 56 \\
\hline
\end{tabular}

the idea of maximising utility in weighing benefits of two or more possible outcomes. The most common example was the weighing of risks and benefits of over- and under-medicating patients in the pursuit of an ideal mean. However, a purely utilitarian conception of beneficence was not always adequate: many events involving beneficence were characterised by an emphasis not so much on achieving good outcomes as on being a benevolent practitioner (an idea better described by virtue theory) and on fostering good relationships with patients (a concept elaborated in feminist relationship theory). In observations, virtue and relationship conceptions of beneficence effectively coincided. Virtue- and relationship-based conceptions of beneficence were far more often voiced amongst nurses (16 events) than doctors (three events). One nurse implied such a perspective on beneficence in the following account of good nursing; note especially the mention of attitudes and the reference to caring and struggling along with the patient.

"Many qualities needed to become a good nurse [as opposed to a good doctor] have more to do with character and morality. ... Somebody with a bright kind of attitude with regard to other human beings could become a good nurse, no matter how unacademically developed. If you don't care, if you don't struggle ... you won't be very much use and won't be a comfort to suffering people."

Engaging in close relationships with patients, however, was not always a matter simply of compassion and affection. It sometimes also involved tension and negative or mixed feelings about difficult patients, an observation already made by Anspach. ${ }^{24}$ A nurse related to me, for example, how one such patient had become "an emotional burden" to the nursing team, a perception that had contributed to the nurses' decision to urge the doctors to refer the patient to another ward.

RESPECT FOR PATIENT AUTONOMY also occupied a prominent place in the moral commitments of staff (figure 3 ). Both occupational groups were highly committed to rights- and rationalitybased views of autonomy, conceptions which are a mainstay of liberal health care ethics. A commitment to patient autonomy qua patient rights common to both doctors (13 events) and nurses (22 events) 


\begin{tabular}{|l|c|c|}
\hline \multicolumn{3}{|c|}{ Figure 3: Conceptions of autonomy by occupational group } \\
\hline & Number of events \\
\hline & Doctors & Nurses \\
\hline Conception of autonomy & & \\
\hline Rights-based & 13 & 22 \\
\hline Rationality-based & 13 & 22 \\
\hline Abilities-based & 6 & 58 \\
\hline Relationship-based & 3 & 34 \\
\hline Total & 35 & 136 \\
\hline
\end{tabular}

\begin{tabular}{|l|l|}
\hline \multicolumn{2}{|c|}{ Figure 4: Conflict between autonomy and beneficence } \\
\hline Within occupational groups & Number of events \\
\hline Doctors & 15 \\
\hline Nurses & 24 \\
\hline $\begin{array}{l}\text { Between occupational groups } \\
\text { Doctors advocating beneficence and nurses advocating } \\
\text { autonomy }\end{array}$ & 8 \\
\hline $\begin{array}{l}\text { Doctors advocating autonomy and nurses advocating } \\
\text { beneficence }\end{array}$ & 1 \\
\hline
\end{tabular}

was evident, for example, in the following comment by a consultant during a ward round, where he conveys his respect for the right of patients of sound mind to make binding advance treatment directives regarding non-psychiatric treatment:

"I was told on the telephone about an advance directive [regarding resuscitation] which had been written a few years ago [by a patient who at the time of writing the directive had been undebatably of sound mind]....It has no legal validity but I think it should be respected...."

A commitment to rationality-based autonomy was also shared by doctors (13 events) and nurses (22 events). For instance, readiness for discharge home, especially for patients recovering from depression, was often perceived to depend upon rationality. With such patients, nurses persistently encouraged "appropriate" or "normal" behaviour, by which terms they referred to a standard of rational autonomy and implied a recovered capacity for the patient to live outside a mental health institution.

Rationality, however, is a very strenuous criterion for autonomy and, as Buchanan and Brock ${ }^{25}$ have noted, there is a whole "complex of ideas giving content to the concept of individual self-determination", or autonomy. Staff on the ward, especially nurses (58 events, compared to six for doctors), also had a strong conception of autonomy as defined by abilities falling short of rational decisionmaking. For example, nurses painstakingly encouraged patients with dementia to be as independent as possible in eating, washing, shaving, etc, with the goal of maintaining maximal autonomy, long after rational decision-making had become an impossible standard.

Consistent with Susan Sherwin's ${ }^{26}$ assertion that Gilligan's $^{11}$ relationship ethics can often be integrated with the principles of more traditional approaches to health care ethics, it was apparent on the ward that nurses (34 events) were also strongly committed to patient autonomy as constituted in relationships; doctors (three events), far less. For the nurses, patients' ability to be self-governing, indeed patients' personhood, appeared to depend on their ability to "meet another person", as one nurse put it. Perhaps a helpful image in explaining this idea of relationship-based autonomy is that of the autistic person, largely incapable of forming relationships, who is therefore in a crucial sense not autonomous. This conception of autonomy is illustrated in a nurse's comment that one sexagenarian patient with rapidly progressing dementia, expressed his selfhood and individuality through "reaching out toward the other [other people] ... [the patient] still does that: he's been able to express great tenderness and humour" despite his dysphasia.

\section{TENSION BETWEEN AUTONOMY AND} BENEFICENCE was the most salient pattern of ethical tension on the ward (see figure 4). Bott doctors and nurses were observed to experience this tension, within and between occupational groups. Within occupational groups (15 events for doctors; 24 for nurses), most of the observed situations were manifestations of tension between rights-based autonomy and utilitarian beneficence. This is logical, since rights protect entitlements of individuals against intrusions (such as those motivated by beneficence) from society or other individuals. One example of such a situation was a doctor's deliberation over whether to admit an apparently suicidal and possibly depressed patient against the patient's will, under the Mental Health Act provision for admission without consent. The doctor was not without doubt that the patient was depressed, but decided to admit her on the grounds that the risk to the patient's health posed by depression justified placing utilitarian beneficence above the patient's autonomy rights.

In cases where nurses and doctors found themselves divided along occupational lines in situations of tension between autonomy and beneficence, nurses were more likely to be advocates of autonomy; doctors, of beneficence. In such situations, nurses were observed on eight occasions to be the prime advocates of autonomy, while doctors had this role on only one occasion observed. The conflict was typically between rightsbased autonomy and utility-based beneficence. In one such case, a severely demented patient consistently and violently resisted intimate care. Nurses 


\begin{tabular}{|l|l|}
\hline \multicolumn{2}{|c|}{ Figure 5: Tension between justice and beneficence } \\
\hline Within occupational groups & Number of events \\
\hline Doctors & 19 \\
\hline Nurses & 11 \\
\hline Between occupational groups & 0 \\
\hline
\end{tabular}

had to restrain her to wash, dress and toilet her. The nurses, who felt "as if we're frog-marching her" were very concerned that they were breaching an inherent right to autonomy, legal rights aside. Doctors were much less concerned, likely because they were at one remove from actually carrying out the violation of the patient's autonomy.

\section{All observed cases of TENSION BETWEEN} JUSTICE AND BENEFICENCE in both occupational groups, involved an egalitarian conception of justice and a utilitarian conception of beneficence towards individuals. I observed 19 such cases amongst doctors, 11 amongst nurses, and none where doctors and nurses took opposing sides (figure 5).

For both doctors and nurses, the most typical conflicts between justice and beneficence concerned the ongoing "beds crisis": egalitarian justice required them to be vigilant for opportunities to discharge patients who had recovered, freeing their beds for others. However, the resulting pressure likely meant that on occasion patients were discharged sooner, or admitted later (if at all), than they would have been had there not been a resource shortage. Tensions between justice and autonomy and between staff self-interest and the three principles were observed too seldom to draw substantive conclusions.

\section{Discussion}

The study's ethnographic methodology proved an apt means of examining everyday ethics. Ethnographically-gathered data confirmed, for the ward in question, Sedgwick's and Fulford's theoretical conclusion that all aspects of health care, even the most uncontroversial, were morally charged. It effectively explored the study's hypothesis that ethical theory can shed light on the approaches of doctors and nurses to patient care. Indeed, the combination of ethnography and ethical theory identified important differences between doctors and nurses in their approaches to patient care. These differences paralleled the study's sociological results, which reveal that members of the two professions, on the ward studied, emphasise different professional goals.

The sociological results help explain the ethical finding that, while both doctors and nurses valued utility-based BENEFICENCE, nurses more than doctors also tended to express commitment to virtue- and relationship-based beneficence. The prime professional goals of nurses were daily care and helping patients live as normally and independently as possible; these goals were pursued through ongoing relationships whose sustenance demanded the demonstration of character virtues. Doctors' most important goals were systematic problemsolving, improving organic function, and research; commitments that emphasise beneficial consequences and fit more readily into an unadulterated utilitarian mould. The doctors' "technological imperative" also conforms to the consequentialist, utilitarian model: the technologies' goal was improved function, regardless of virtue or relationships. Different professional roles, therefore, appear to account here for differences in ethical approaches. It should be noted, however, that, although doctors spoke less often of virtue, one cannot necessarily infer that doctors have a weaker conception of benevolence as a characteristic of a virtuous doctor: it may be that doctors are highly motivated by such a conception but that their socialisation process, directed along scientific, outcome-based lines, teaches them to mask this conception with utilitarian expressions of beneficence.

Also, the closer relationships at the root of nurses' apparently different conception of beneficence need not always signify superior concern for patiens welfare: nurses' frustration with problem-patients on the ward sometimes contributed to the precipitate transfer of patients or led nurses to avoid patients. Doctors maintained more distance from patients and correspondingly expressed less frustration with difficult ones. Thus there appear to be beneficencerelated advantages and disadvantages both of nurses' close relationships with patients, and of doctors' disengagement. Nurses can foster patients' social wellbeing and are attuned to their individual needs, while doctors are assiduous in trying to solve problems of dysfunction; nurses risk making decisions coloured by frustration with problempatients, while doctors risk lacking sensitivity to individual cases. The advantage of the doctors' perspective is the converse of the disadvantage of the nurses', and vice versa, suggesting that open communication and shared decision-making between nurses and doctors is in patients' best interests.

The sociological case study also sheds light on the results regarding RESPECT FOR PATIENT AUTONOMY. Nurses' relative emphasis of autonomy based on abilities other than rationality can be partly explained by the fact that nurses' most salient professional goal, patient normality and independence, is defined by patients' abilities, including, but never limited to, rationality. Similarly, relationships between carers and patients, and therefore relationship-based conceptions of autonomy, are far more likely to be built through daily care another of the nurses' characteristic professional 
goals - than through the more episodic patient contact typical of doctors.

Also, the observation that, when TENSION BETWEEN BENEFICENCE AND RESPECT FOR PATIENT AUTONOMY involved doctors on one side and nurses on the other, nurses seemed more likely to support autonomy (typically rightsbased), while doctors in such situations usually advocated beneficence (typically utility-based), may be explained by nurses' closer relationships and closer identification with patients. Doctors, on the other hand, appeared most concerned with problemsolving and improving organic function, consequentialist goals sometimes inconsistent with rights-based autonomy.

The germ of this study was scepticism among health practitioners and academics that ethical theory, especially the principles-based mainstream, can usefully describe the approaches of doctors and nurses to patient care. The study is original in melding ethnography and ethical theory to explore the relevance of the various theoretical approaches, empirically. The results confirm that ethical theory can shed light on the moral considerations present in the everyday provision of health care. Specifically, these results usefully describe the ethical approaches of doctors and nurses and, moreover, significant differences between the occupational groups. In conclusion, principles-based ethical theory can, if supplemented by feminist and virtue theory, describe ethics in practice, and thus has potential to help doctors and nurses articulate and refine their own ethical values, as well as understand those of others. The following recommendations suggest that ethical theory tested empirically for practical relevance could lead health-care professionals to heightened awareness of the ethical nature of their work, a more democratic approach to addressing practical moral dilemmas, and, ultimately, better clinical decisionmaking.

\section{Considerations for doctors, nurses and researchers}

For practice: Decision-making by doctors and nurses can stand to profit from an understanding of the ethical priorities shared by the two groups, and of the ways in which the groups' priorities diverge. Such an understanding could give doctors and nurses insight into each others' strengths and weaknesses as ethical-decision makers, and improve their ability to complement each other in making decisions, ultimately to the benefit of the patient.

For teaching: The study reveals (a) that everyday practice abounds in ethically charged situations, and (b) that health care professionals are discussing these issues, even if not in explicitly ethical terms. Everyday practice can therefore serve as a rich environment for medical and nursing students in which to learn ethics. Educators should take advantage of this, in keeping also with other work ${ }^{27} 28$ suggesting the relevance of real cases and students' clinical experience in ethics education.

For future research: Future ethnographic-ethical research could build on the findings of this study by pursuing the same research questions using similar methodology in fields other than psychiatry, with a view to drawing more generally applicable conclusions. It would also be useful to seek to identify optimal conditions for the resolution of ethical tensions in health care settings.

\section{Acknowledgements}

I am grateful to the staff and patients on the ward and to my MPhil. supervisors, Professor K W M Fulford, Ms J Garcia, and Professor S Ringen, for their helpful and extensive comments on the research, which was supported by a joint scholarship from the Social Science and Humanities Research Council of Canada and the Natural Science and Engineering Research Council of Canada.

David W Robertson, BASc, MPhil, was a master's student in Comparative Social Research at the University of Oxford while conducting this study. At present he is a medical student at the University of Toronto, Canada.

\section{References}

1 Fox R, Swazey J. Medical morality is not bioethics medical ethics in China and the United States. Perspectives in Biology and Medicine 1984; 27, 3: 336-60.

2 Baron RJ. Dogmatics, empirics, and moral medicine. Hastings Center Report 1989; 19, 1: 41.

3 Hoffmaster B. Can ethnography save the life of medical ethics? Social Science and Medicine 1992; 35: 1421-31.

4 I would refer readers unfamiliar with ethnography to Lincoln Y, Guba E. Naturalistic inquiry. Beverly Hills: Sage, 1985.

5 Fulford K W M. Moral theory and medical practice. Cambridge: Cambridge University Press, 1989.

6 Reiser SJ, Bursztajn HJ, Appelbaum PS, Gutheil TG. Divided staffs, divided selves: a case approach to mental health ethics. Cambridge: Cambridge University Press, 1987.

7 Sedgwick P. Psycho politics. London: Pluto Press, 1982.

8 Beauchamp TL, Childress JF. Principles of biomedical ethics [4th ed]. New York: Oxford University Press, 1994.

9 Gillon R. Philosophical medical ethics. Chichester: John Wiley and Sons, 1985.

10 See Macintyre A. After virtue: a study in moral theory. London: Duckworth, 1981.

11 See Gilligan C. In a different voice: psychological theory and women's morai development. Cambridge, Massachusetts: Harvard University Press, 1982.

12 Sulmasy DP, Geller G, Levine D, Faden R. Medical house officers' knowledge, attitudes, and confidence regarding medical ethics. Archives of Internal Medicine 1990; 150: 2509-13. 
13 Sulmasy DP, Geller G, Levine D, Faden R. A randomized trial of ethics education for medical house officers. Fournal of Medical Ethics 1993; 19: 157-63.

14 Hébert $P$, Meslin E, Dunn E, Byrne N, Ried S. Evaluating ethical sensitivity in medical students: using vignettes as an instrument. Fournal of Medical Ethics 1990; 16: 141-5.

15 Mitchell KR, Myser C, Kerridge IH. Assessing the clinical ethical competence of undergraduate medical students. Fournal of Medical Ethics 1993; 19: 230-6.

16 Sulmasy DP, Geller G, Faden R, Levine D. The quality of mercy: caring for patients with 'do no resuscitate' orders. Fournal of the American Medical Association 1992; 268, 4: 471-2.

17 Guillemin JH, Holmstrom LL. Mixed blessings: intensive care for newborns. New York: Oxford University Press, 1986.

18 Anspach RR. Deciding who lives: fateful choices in the intensive care nursery. Berkeley: University of California Press, 1993.

19 Frohock, FM. Special care: medical decisions at the beginning of life. Chicago: University of Chicago Press, 1986.

20 Lieban RW. Medical anthropology and the comparative study of medical ethics. In: Weisz G, ed. Social science perspectives on medical ethics. Philadelphia: University of Pennsylvania Press, 1991.
21 Jennings B. Ethics and ethnography in neonatal intensive care. Social science perspectives on medical ethics. Philadelphia: University of Pennsylvania Press, 1991.

22 Miles MB, Huberman AM. Qualitative data analysis: an expanded sourcebook [2nd ed]. Thousand Oaks: Sage, 1994.

23 Burnard P. A method of analysing interview transcripts in qualitative research. Nurse Education Today 1991; 11, 6: 461-6.

24 Anspach RR. Prognostic conflict in life-and-death decisions: the organization as an ecology of knowledge. Fournal of Health and Human Behaviour 1987; 28, 3: 215-31.

25 Buchanan AE, Brock DW. Deciding for others: the ethics of surrogate decision making. Cambridge: Cambridge University Press, 1989.

26 Sherwin S. No longer patient: feminist ethics and health care. Philadelphia: Temple University Press, 1992.

27 Osborne LW, Martin CM. The importance of listening to medical students' experience when teaching them medical ethics. Fournal of Medical Ethics 1989; 15: 35-8.

28 Hope A, Fulford KWM. Medical education: patients, principles and practice skills. In: Gillon $\mathbf{R}$, ed. Principles of health care ethics. Chichester: John Wiley and Sons, 1994.

\section{News and notes}

\section{Gene therapy - Current Clinical Status}

Henry Stewart Conference studies are presenting a conference on Gene Therapy - Current Clinical Status on Tuesday 29 October 1996 at The Café Royal, London W1.

This one-day course has been designed as an intensive update on the results so far in clinical trials of gene therapy for various diseases. The speakers will address the issues that have arisen to date in the clinical trials, what has been learnt and where they expect progress will be made in the future.
The event will be chaired by Professor Karol Sikora and the international panel of speakers includes Professor Jack Roth (University of Texas M D Anderson Cancer Center), Professor Angus Dalgleish (St George's Hospital Medical School) and Professor Jonathan Weber (Imperial College of Medicine at St Mary's).

Further enquiries to Nicola McCall at Henry Stewart Conference Studies on: Tel: +44 (0) 171404 3040; Fax: +44 (0) $171 \quad 404$ 2081; e-mail: 100622.3264@compuserve.com 